\title{
Ethephon Stimulation and Yield Response of Some Hevea Clones in the Humid Forests of South West Cameroon
}

\author{
J. N. Njukeng, P. M. Muenyi, B. K. Ngane, and E. E. Ehabe \\ Ekona Regional Research Centre, Institute of Agricultural Research for Development (IRAD), PMB 25, Buea, Cameroon \\ Correspondence should be addressed to J. N. Njukeng, jnkengafac@yahoo.com
}

Received 30 March 2011; Revised 10 July 2011; Accepted 11 July 2011

Academic Editor: M. Tejada

Copyright ( $2011 \mathrm{~J}$. N. Njukeng et al. This is an open access article distributed under the Creative Commons Attribution License, which permits unrestricted use, distribution, and reproduction in any medium, provided the original work is properly cited.

\begin{abstract}
Several exploitation systems are being used today to sustainably improve dry rubber production by the rubber tree (Hevea brasiliensis). These involve different combinations of tapping frequencies, cut lengths, stimulation frequencies, and stimulant concentrations. Such combinations are much easier to ascertain for confirmed clones as opposed to new introductions, for which extensive testing is required. A study was therefore conducted in the South West region of Cameroon characterized by a monomodal rainfall regime (one dry and one rainy season) to evaluate yield response to Ethephon stimulation (conc. 2.5\%) of some newly introduced rubber clones (IRCA 18, IRCA 19, RRIC 100, and RRIC 110) for large-scale planting in Cameroon. Generally, annual yields and tree productivity ranged between the referenced clones tested: some closer to the intermediate yielding GT 1 (IRCA 18 and IRCA 19) and others to the high yielding PB clones (RRIC 100 and RRIC 110) indicating thereby the possible convenient adoption of some established exploitation regimes for these new introductions. Climatic factors like cumulative rainfall and relative humidity conditioned rubber yields of clones tested and considerably accounted for yield variations. These results could be used as a first step towards deriving regional climate models for predicting rubber yields, especially in an era of global climate change.
\end{abstract}

\section{Introduction}

Latex from the rubber tree, Hevea brasiliensis, is produced in specialized cells, laticifers, located within the bark of the tree. On incising the tree's bark, in a process called "tapping," the latex oozes out and is collected. The quantity of latex obtained after successive tappings depends on how easily the latex flows [1], the duration of flow [2], and the rate of latex regeneration within the tree $[3,4]$.

The tree bark serves therefore as the farm capital as its quality conditions the quantity of latex regenerated during successive tappings [5]. Therefore, to ensure sustained exploitation, lower tapping frequencies are widely adopted. However, to compensate for yield reductions that accompany reduced tapping frequencies, chemical yield stimulants are applied [6], the most common of which is the ethylene-generating product, 2-chloroethyl phosphonic acid, marketed worldwide as Ethrel or Ethephon. When applied on the tree's tapping cut, released ethylene gas increases the duration of latex flow by delaying plugging of latex vessels [7]. For optimum yields to be obtained, the frequency of stimulation and the concentration of stimulant should be modulated as a function of the clone, tree age, and tapping system [8]. Moderate tapping systems were suggested to be used for precocious clones because they are very sensitive to stress. However, reduction in frequency of tapping could enhance precoagulation as the latex tends to have higher dry rubber contents and so flow less easily, and as such higher stimulation frequencies are often recommended for some clones [9]. However, for high and sustained yields to be obtained, suitable tapping and stimulation systems must be adopted which have little or no deleterious effects on tree growth, bark renewal, and appearance of the phenomenon of bark dryness [6].

Although clone type has been found to be a limiting factor affecting rubber productivity, climatic variability seems to represent another cause of reduced agricultural productivity [10], especially the yield response of Hevea brasiliensis after stimulation $[11,12]$. Considering that rain-fed husbandry is commonplace during crop cultivation in Cameroon, there is dire need to evaluate crop-yield-weather relationships, especially those characterizing perennial 
cropping systems like the Hevea, in an area where rainfall is not limiting, especially when newly introduced clones are involved whose recommended tapping frequencies are known. Such testing for eventual large-scale planting, involves evaluation of the most limiting parameters. A trial was therefore conducted to evaluate yield responses of different newly introduced clones in the humid forest zones of Cameroon when subjected to different stimulation frequencies.

\section{Material and Methods}

2.1. Experimental Site. This study was carried out from January 1998 to December 2001 in the Sonne Rubber Estate of the Cameroon Development Corporation (CDC) in South West Cameroon. This area is characterized by a monomodal rainfall regime, with a marked long wet season and a short dry season. Two main seasons could be distinguished separated by an intermediate season:

(i) Mid-June to October: a major rainy season of overcast and misty weather, continuous rains, and drizzle;

(ii) mid-November to mid-March: a major dry season of dry and foggy weather, Harmattan and diffuse radiance;

(iii) mid-October to mid-November/mid-March to midJune: intermediate seasons of changeable weather, storms and rain showers alternating with bright intervals.

2.2. Planting Material. This study involved seven Hevea brasiliensis clones: three already recommended for large-scale planting in Cameroon (GT1, PB 235 and PB 260) and four newly introduced ones (IRCA 18, IRCA 19, RRIC 100, and RRIC 110). The trees had been planted in 1990 and opened for tapping in 1997 at $150 \mathrm{~cm}$ height. Tapping was on panel B0-1, and all trees were tapped every four days on half spiral (tapping system: $1 / 2 \mathrm{~S} \mathrm{D} / 4$ ). In the event tapping could not be carried out due to bad weather, and the task was recovered the next day. The field layout was a randomized complete block design with three treatments, replicated four times. The treatments involved included fields that were subjected to no stimulation (Treatment I), tree stimulation with $2.5 \%$ Ethephon, four rounds a year (Treatment II-stimulated in April, May, October and November), and stimulation with 2.5\% Ethephon, eleven rounds a year (Treatment III-stimulated monthly except in the month of March).

Each experimental unit had about 176 theoretical trees (8 lines of 22 trees each) covering an area of about 0.35 ha.

The 2.5\% Ethephon mixture was obtained following dilution with water of a $10 \%$ Ethephon stock solution and applied using a brush on the tapping panel such that each tree received $1 \mathrm{~mL}$ of the product or $1 \mathrm{mg}$ a.i. per application.

2.3. Data Collection and Analysis. Every fortnight, coagula from each experimental unit were collected and weighed (to $100 \mathrm{~g}$, using a Salter hanging balance) and the tree productivity, in $g$ per tree per tapping, calculated.
Climatic data were obtained from the Meteorological Station of the CDC in the town of Tiko, situated less than $1 \mathrm{~km}$ from the trial plot.

Data collected was subjected to a two-factor analysis of variance (clones and stimulation treatments) and analysed using the GenStat Version 7.2 statistical package (Lawes Agricultural Trust, 2007) [13].

Treatment and clonal yields were compared and pairwise correlations computed between yield data and available climatic data in the event where such relationships were considered to have been linear, after having initially plotted the trends and determined the significance of the equations' coefficients of determination $\left(R^{2}\right)$.

\section{Results and Discussion}

3.1. Seasonal Variations in Yield Response. Results on seasonal variations in the productivity of trees of the various clones studied showed very similar patterns, irrespective of the number of stimulation rounds to which the trees were subjected (Figure 1): increasing from the month of April (when tapping restarts), attaining a likely summit in July, and remaining at this plateau till November after which it starts decreasing to reach a minimum in February.

Although significant seasonal variations were observed of the tree productivity $(P<0.001)$ and of the effect of clones $(P=0.009)$, there was no significant interaction between the two factors $(P=0.96)$. The trends in monthly productivity were obvious from the plot of the seasonal evolution in tree productivity for trees not stimulated (Figure 1(a)), trees receiving quarterly stimulation rounds (four a year, Figure 1(b)) and those receiving as much as monthly rounds (eleven a year, Figure 1(c)). However, tree productivity was lowest for trees receiving the highest rounds of stimulant application (11 rounds). These trends are obvious because, by the month of February, most trees have lost their leaves and photosynthetic activity is minimal, hence low latex production. Similarly, when trees are just reopened for tapping after the observed rest (April), some lapse of time is needed before the trees' metabolism is fully activated to give optimal yields.

Generally trees of clones RRIC 110, IRCA 18 and IRCA 19 had the lowest productivity while those of clones RRIC 100, GT 1 and PB 260, had the highest.

3.2. Clonal Variations in Yield Response. Results obtained showed that the rubber yields (Figure 2) and tree productivity (Figure 3) varied with the clone tested, and for each particular clone, the stimulation treatments applied.

On the whole, application of Ethephon as compared to treatments with no stimulation led to a significant increase in annual yields for all the clones tested (Figure 2). Some differences were nonetheless noted when annual yield results were compared for the two treatments with stimulant application. Comparing Ethephon application at 4 rounds annually with the no application treatment, applicant of the stimulant was much superior for most of the clones except for the GT 1, IRCA 19, and PB 260. This resemblance however disappeared when the trees were treated to 11 rounds of stimulant 


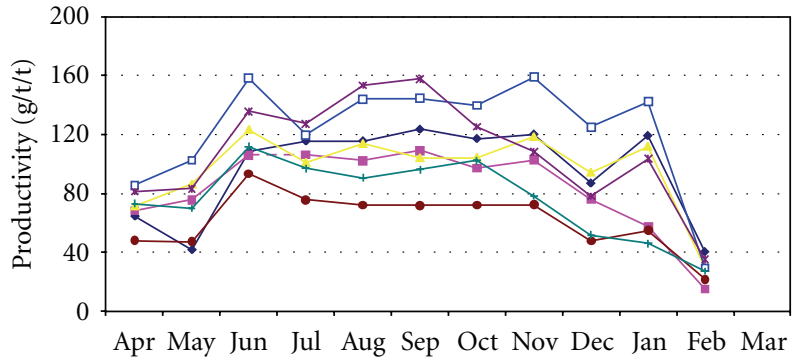

(a)

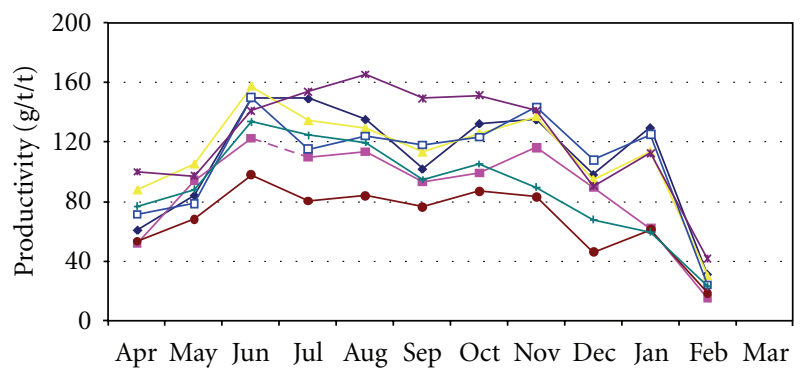

(b)

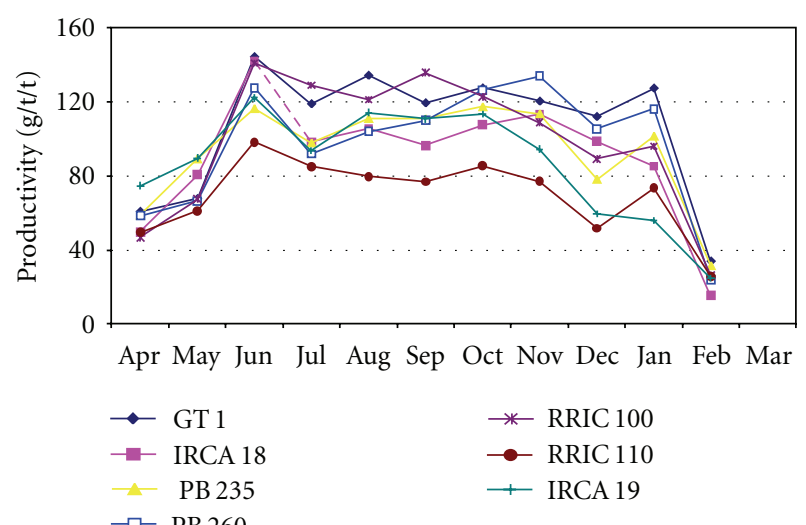

(c)

FIGURE 1: Seasonal variations in yields of the various clones subjected to (a) no chemical stimulation, (b) stimulation with 4 rounds Ethephon, and (c) stimulation with 11 rounds Ethephon.

annually. In the latter case, clones which had shown no improvement over no application with 4 rounds of application (GT 1, IRCA 19, and PB 260) became much more superior. The field productions of the other clones (IRCA 18, PB 235, RRIC 100, and RRIC 110) were virtually the same for trees stimulated with 4 or 11 rounds annually.

The effects of the various rounds of stimulant application were much similar, though with some slight variations, on the productivity of the rubber trees to what was obtained on the annual field production (Figure 3). Similar to results on the annual production, Ethephon application at 4 rounds annually performed almost the same as treatments with no stimulant application for some given clones (GT 1, IRCA 19, and PB 260). These clones, nonetheless, performed much better when the trees were subjected to 11 rounds of application of the stimulant. Results obtained on annual yields showed that the response of the newly introduced clones

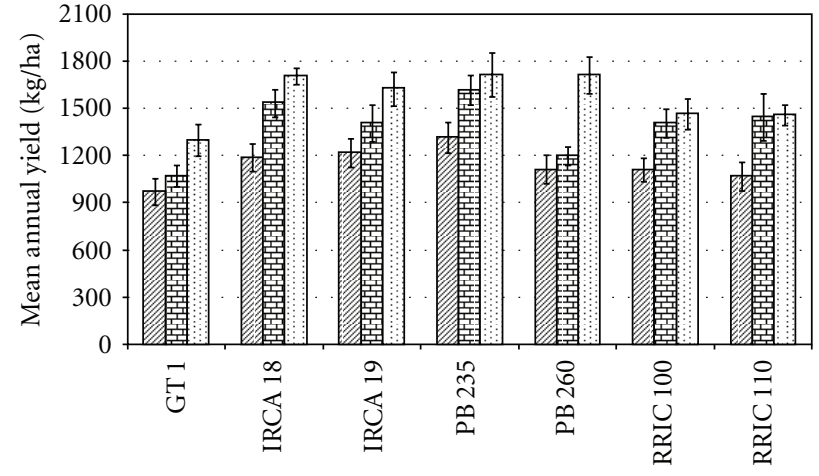

$\square$ No stimulation

巴 Stimulation: four rounds a year

$\square$ Stimulation: eleven rounds a year

Figure 2: Clonal variations in annual fields for the various clones. Vertical bars represent standard errors of means (SEM) for each clone and treatment.

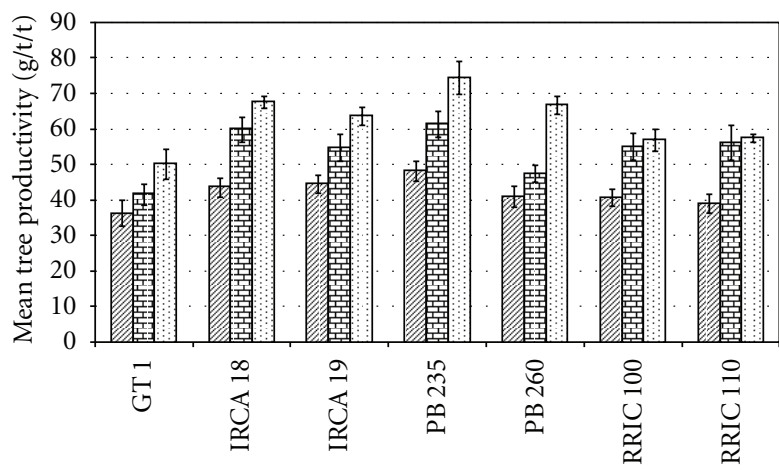

■o stimulation

田 Stimulation: four rounds a year

$\square$ Stimulation: eleven rounds a year

FIGURE 3: Clonal variations in tree productivity for the various clones. Vertical bars represent standard errors of means (SEM) for each clone and treatment.

(IRCA 18, IRCA 19, RRIC 100, and RRIC 110) was similar to the GT 1 clone.

Earlier research has led to ascertaining that response to stimulant application varies considerably with the clone concerned. In response to this, confirmed clones have been classified under different classes (low, intermediate, and high) depending on their inherent rates of metabolism. Hence, a reference clone like the Clone PB 235 is considered a high yielding clone while the clone GT 1 is classified as an intermediate metabolic clone [14].

Results obtained on tree productivity show that clone PB 260 is closer in performance to the clone PB 235, while the newly introduced clones (IRCA 18, IRCA 19, RRIC 100, and RRIC 110) performed similarly to the GT 1 . This study confirms these newly introduced clones as generally high yielding [12], show similar physiological profiles to the GT 1 (of intermediate metabolic activity), and could be exploited similarly. No low metabolic clone was found among the new 
TABLE 1: Correlation coefficients between yield and weather variables.

\begin{tabular}{|c|c|c|c|c|c|}
\hline Yields & Clone & $\begin{array}{l}\text { Cumulative rainfall } \\
\qquad(\mathrm{mm})\end{array}$ & Days of insolation & Mean temperature & Mean relative humidity \\
\hline \multirow{7}{*}{$\begin{array}{l}\text { Field production } \\
(\mathrm{kg} / \mathrm{ha})\end{array}$} & GT 1 & $0.8046^{* *}$ & -0.4763 & $-0.8084^{* *}$ & $0.8337^{* *}$ \\
\hline & IRCA 18 & $0.7173^{* *}$ & $-0.7705^{* *}$ & -0.4506 & $0.6273^{*}$ \\
\hline & IRCA 19 & $0.6528^{*}$ & -0.2026 & $-0.6067^{*}$ & $0.8264^{* *}$ \\
\hline & PB 235 & $0.7558^{* *}$ & $-0.6529^{*}$ & $-0.8139^{* *}$ & $0.6147^{*}$ \\
\hline & PB 260 & 0.5524 & -0.4637 & $-0.6094^{*}$ & 0.5205 \\
\hline & RRIC 100 & -0.0883 & -0.2171 & -0.0741 & -0.0094 \\
\hline & RRIC 110 & $0.7438^{* *}$ & -0.3517 & $-0.692^{*}$ & $0.738^{* *}$ \\
\hline \multirow{7}{*}{$\begin{array}{l}\text { Tree productivity } \\
(\mathrm{g} / \mathrm{t} / \mathrm{t})\end{array}$} & GT 1 & $0.8432^{* *}$ & $-0.6025^{*}$ & $-0.8481^{* *}$ & $0.7011^{*}$ \\
\hline & IRCA 18 & 0.562 & $-0.6156^{*}$ & -0.2197 & 0.2983 \\
\hline & IRCA 19 & $0.6024^{*}$ & -0.2388 & -0.5369 & $0.5979 *$ \\
\hline & PB 235 & $0.6102 *$ & -0.5444 & $-0.6749^{*}$ & 0.5257 \\
\hline & PB 260 & 0.4454 & -0.4981 & -0.5089 & 0.2663 \\
\hline & RRIC 100 & $0.7432^{* *}$ & -0.6047 & -0.7737 & 0.5794 \\
\hline & RRIC 110 & $0.6792 *$ & -0.3864 & $-0.6133^{*}$ & 0.501 \\
\hline
\end{tabular}

Significant at $* * 1 \% ; * 5 \%$.

introductions as all of them seemed to respond favourably to the different rounds of stimulation. The timid response of some clones to low stimulation (4 rounds annually) could indicate that the rounds were much insufficient for a proper activation of the trees' tapping panels and need much intensified stimulation. The absence of any considerable differences between treatments with 4 and 11 rounds of stimulant application for some clones will lead to suggesting that a slightly more intensive regime like 6 rounds of annual application, which is more than 4 rounds and less than 11 rounds, could be more appropriate. This must however be confirmed with results on the composition of harvest latex and their influence on the trees' physiological states.

In fact, similar situations have been recorded elsewhere that seemed to confirm the poor productive performance of some clones when they receive no stimulant as is the case with clone PB 260 tapped on Panel BO-1 [13]. Indeed, for best response to Ethephon stimulation, the stimulation intensity should increase when clonal latex metabolic activity decreases [14].

3.3. Relationships between Yields and Climatic Data. The results of pairwise correlations between yields and some weather variables (cumulative rainfall, number of insolation hours, mean daily temperatures, and mean relative humidity) are presented in Table 1. Except for clones PB 260 and RRIC 100, significant positive correlations were found between cumulative rainfall and yields for all the clones considered. This indicates a tight relationship between on the one hand, latex regeneration within the laticiferous cells, the ease and quantity of latex flow of shows and water availability, on the other hand. Rain provides moisture for the soil which is absorbed by the tree's roots thus making latex more diluted and free flowing. At low soil moisture levels, the rate and duration of latex flow are much reduced.

Similar results have been obtained elsewhere where response to chemical yield stimulation was found to be influenced by climate and soil moisture, especially the cumulative rainfall during the months preceding stimulation [12]. The quality of such results could, however, be subject to much mitigation when the incidence of rainfall on the number of tapping days is taken into consideration [15]. Awotoye and Matthew [16], working on some annual crops in Nigeria, showed a reasonable relationship between crop yield and climate variability, particularly the temporal change in amounts of rainfall and obtained very high crop yields in a year that was preceded by a very wet dry season and high annual rainfall. In a similar manner, results of this study showed significant positive relations between relative atmospheric humidity and rubber yields for most of the clones studied (cf. Table 1). This positive relationship is explained by the rather low transpiration and water loss that reign at high relative humidity. The resulting high pressure potential in the latex vessels facilitates latex flow [17].

Results obtained in this study equally showed that the number of insolation hours as well as the mean daily temperatures were often not directly correlated with yields, at times negatively, as were the observations of Rao et al. [18] who studied the performance of five Hevea brasiliensis clones in the Agartala region in India. Elsewhere, yields of clone PB 235 (amongst others) could be negatively correlated with minimum daily temperatures [19].

Principal component analysis of experimental data showed that at least half of obtained rubber yields for most of the clones could be accounted for by variations in cumulative rainfall, mean daily temperature, and daily relative humidity, results that have been confirmed elsewhere [12].

\section{Conclusion}

Several tapping systems used to improve latex and dry rubber production by the rubber tree involve the use of different combinations of tapping frequencies, cut lengths, stimulation frequencies, and stimulant concentrations. A study was 
conducted to evaluate the production potential and response to chemical stimulation of some newly introduced clones in Cameroon.

Whereas a significant effect of stimulant application was observed irrespective of clone, yield response of IRCA clones (IRCA 18 and IRCA 19) was closer to the high yielding PB clones while the RRIC clones (RRIC 100 and RRIC 110) were closer to the intermediate yielding GT 1. The stimulation and exploitation regimes of these referenced clones could therefore be conveniently adopted for the new introductions. Climatic factors like cumulative rainfall conditioned the rubber yields in the clones studied and accounted for as much as half of yield variations. These results could be used as a first step towards deriving regional climate models for the prediction of rubber yields, especially in an era of global climate change.

\section{Acknowledgment}

The authors gratefully acknowledge the logistic and other support received from the management and staff of the Cameroon Development Cooperation (CDC).

\section{References}

[1] F. C. Low, "Distribution and concentration of major soluble carbohydrates in Hevea latex, the effect of ethephon stimulation and the possible role of these carbohydrates in latex flow," Journal of the Rubber Research Institute of Malaysia, vol. 26, no. 21, 1978.

[2] W. A. Southorn, "Physiology of Hevea (latex flow)," Journal of the Rubber Research Institute of Malaysia, vol. 21, pp. 494-512, 1969.

[3] J. L. Jacob, J. C. Prevot, D. Roussel et al., "Yield-limiting factors, latex physiological parameters, latex diagnosis and clonal typology," in Physiology of Rubber Tree Latex, J. L. Jacob, J. d'Auzac, and H. Chrétin, Eds., pp. 345-382, CRC Press, Boca Raton, Fla, USA, 1989.

[4] J. M. Eschbach and R. Lacrotte, "Factors influencing response to hormonal yield stimulation: limits of this stimulation," in Physiology of Rubber Tree Latex, J. L. Jacob, J. d'Auzac, and H. Chrétin, Eds., p. 321, CRC Press, Boca Raton, Fla, USA, 1986.

[5] V. H. F. Moraes and L. A. C. Moraes, "Effect of rubber tree (Hevea spp.) budded crowns on the content of magnesium and latex regeneration of the clone Fx 3899," Agrotropica, vol. 9, pp. 59-66, 1997.

[6] J. M. Eschbach and Y. Banchi, "Advantages of Ethrel stimulation in association with reduced tapping intensity in the Ivory Coast," Planter, vol. 61, pp. 555-567, 1985.

[7] X. Wenxian, W. Xiaodi, and P. Yanqing, "A review of studies on exploitation with ethephon: stimulation and proposals for new panel planning in China," in Proceedings of the IRRDB Rubber Physiology and Exploitation Meeting, pp. 21-32, Hainan, China, December 1986.

[8] S. Sivakumaran, S. W. Pakianathan, and D. Abraham, "Longterm stimulation. Effect of continuous Ethephon stimulation with low frequency tapping systems," Journal of Rubber Research Institute of Malaysia, vol. 30, no. 3, pp. 174-196, 1982.

[9] P. d. S. Goncalves, S. R. d. Souza, A. P. Brioschi, A. d. C. V. Filho, A. May, and R. S. C. Alarcon, "Effect of tapping frequency and stimulation on yield and economic peformance of rubber tree clones-efeito da frequencia de sangria e estimulacao no desempenho produtivo e economico de clones de seringueira," Pesquisa Agropecuaria Brasileira, vol. 35, no. 6, pp. 1081-1091, 2000.

[10] S. O. Agele, "Response of sunflower to weather variations in a tropical rainforest zone," in Proceedings of the African Crop Science Society Conference, vol. 6, pp. 1-8, African Crop Science Society, Nairobi, Kenya, 2003.

[11] Y. le Roux, E. E. Ehabe, J. Sainte-Beuve et al., "Seasonal and clonal variations in the latex and raw rubber of Hevea brasiliensis," Journal of Rubber Research, vol. 3, no. 3, pp. 142-156, 2000.

[12] P. J. George and C. K. Jacob, Eds., Natural Rubber Agromanagement and Crop Processing, Rubber Research Institute of India, Rubber board, Kottayam, India, 2000.

[13] Genstat ${ }^{\circledR}$ Version 7.2 statistical package (Lawes Agricultural Trust), 2007.

[14] J. M. Eschbach, "Clone GT 1: possibilités de réduction de la fréquence de saignée," Revue Générale des Caoutchoucs et Plastiques, vol. 659, pp. 165-168, 1986.

[15] A. O. P Odjugo and C.I. Ikhile, "Impact of climatic conditions and tapping time on the yield of rubber (Hevea brasiliensis) in mid-western Nigeria," Tropical Agriculture, vol. 81, no. 1, pp. $7-10,2004$.

[16] O. O. Awotoye and O. J. Matthew, "Effects of temporal changes in climate variables on crop production in tropical sub-humid South-Western Nigeria," African Journal of Environmental Science and Technology, vol. 4, no. 8, pp. 500-505, 2010.

[17] A. S. Devakumar, G. G. Rao, R. Rajagopal et al., "Studies on soil-plant-atmosphere system in Hevea: 2. seasonal effects on water relations and yield," Indian Journal of Natural Rubber Research, vol. 1, pp. 45-60, 1988.

[18] P. S. Rao, C. K. Saraswathyamma, and M. R. Sethuraj, "Studies on the relationship between yield and meteorological parameters of para rubber tree (Hevea brasiliensis)," Agricultural and Forest Meteorology, vol. 90, no. 3, pp. 235-245, 1998.

[19] P. M. Priyadarshan, "Contributions of weather variables for specific adaptation of rubber tree (Hevea brasiliensis Muell.Arg) clones," Genetics and Molecular Biology, vol. 26, no. 4, pp. 435-440, 2003. 


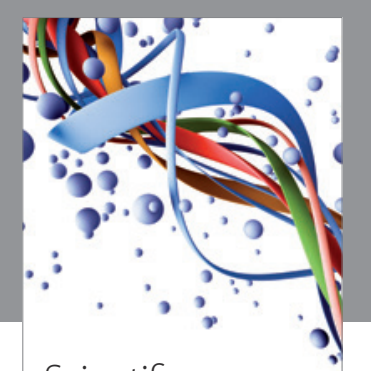

Scientifica
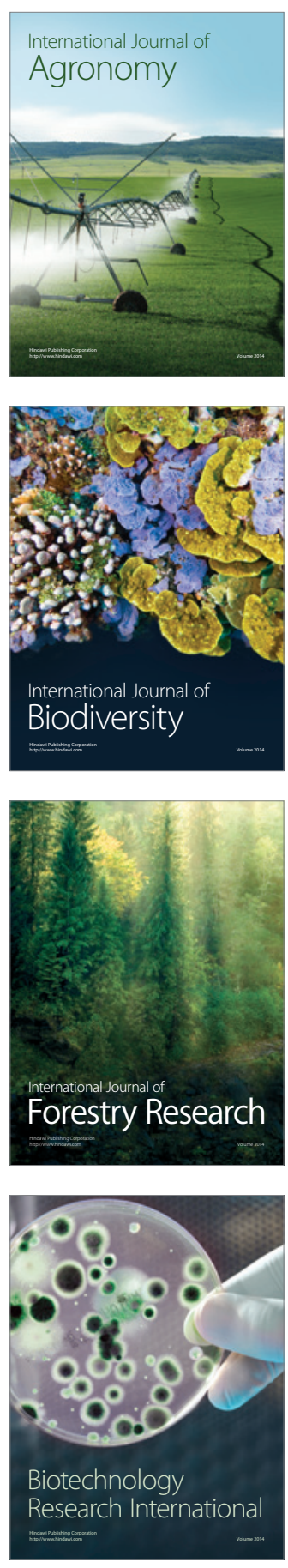
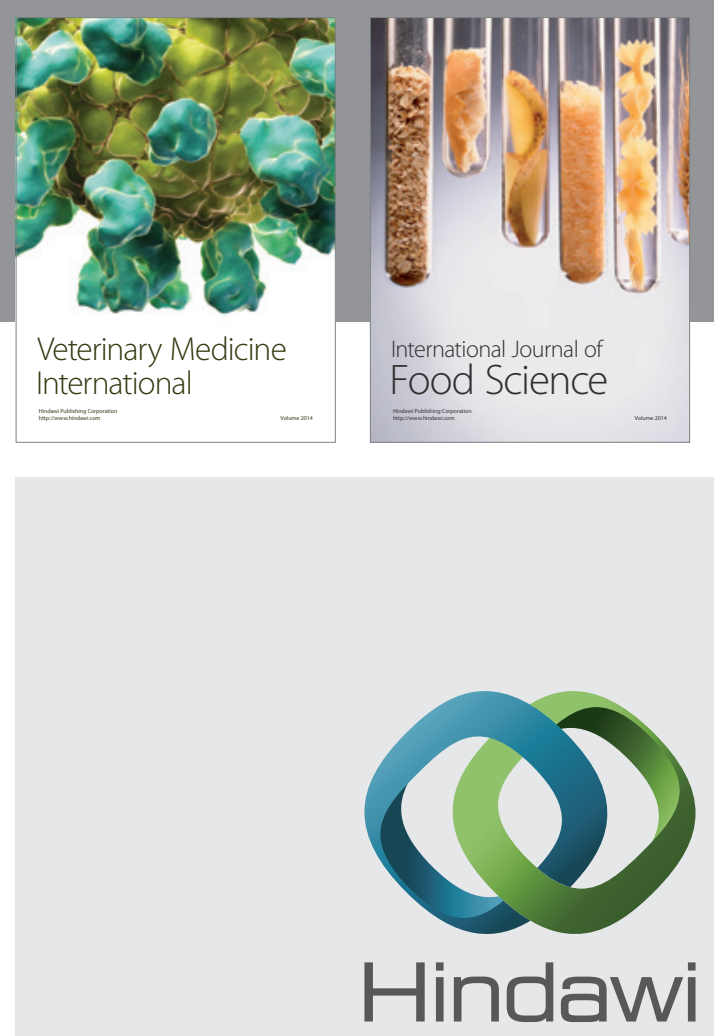

Submit your manuscripts at

http://www.hindawi.com
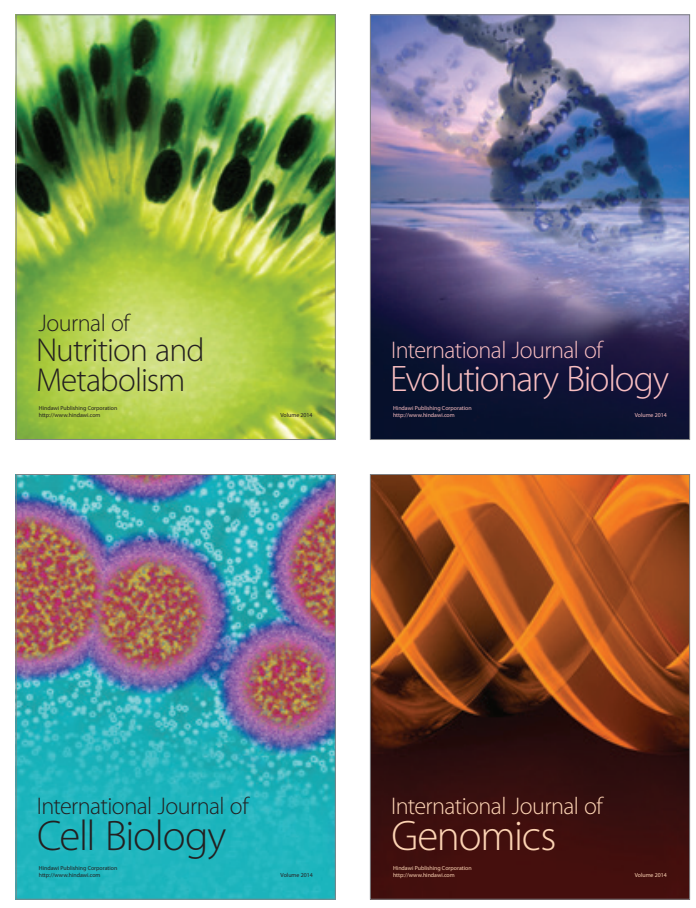
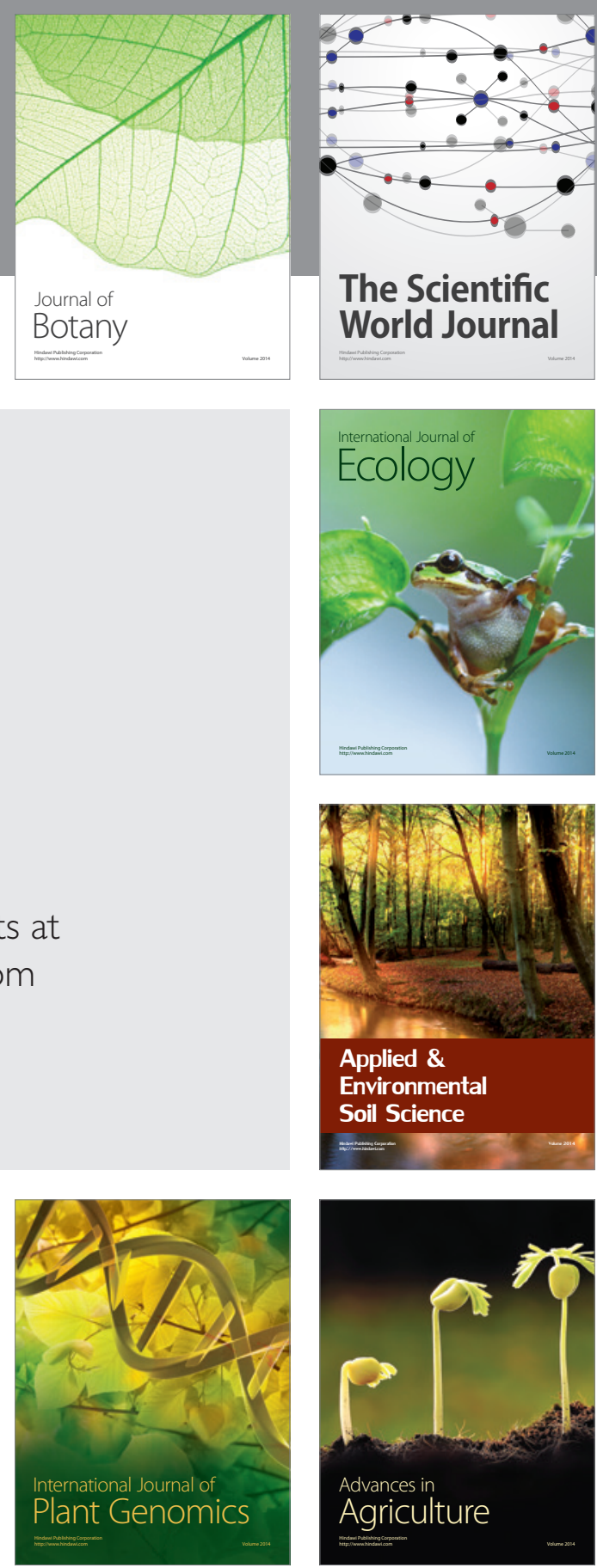

The Scientific World Journal
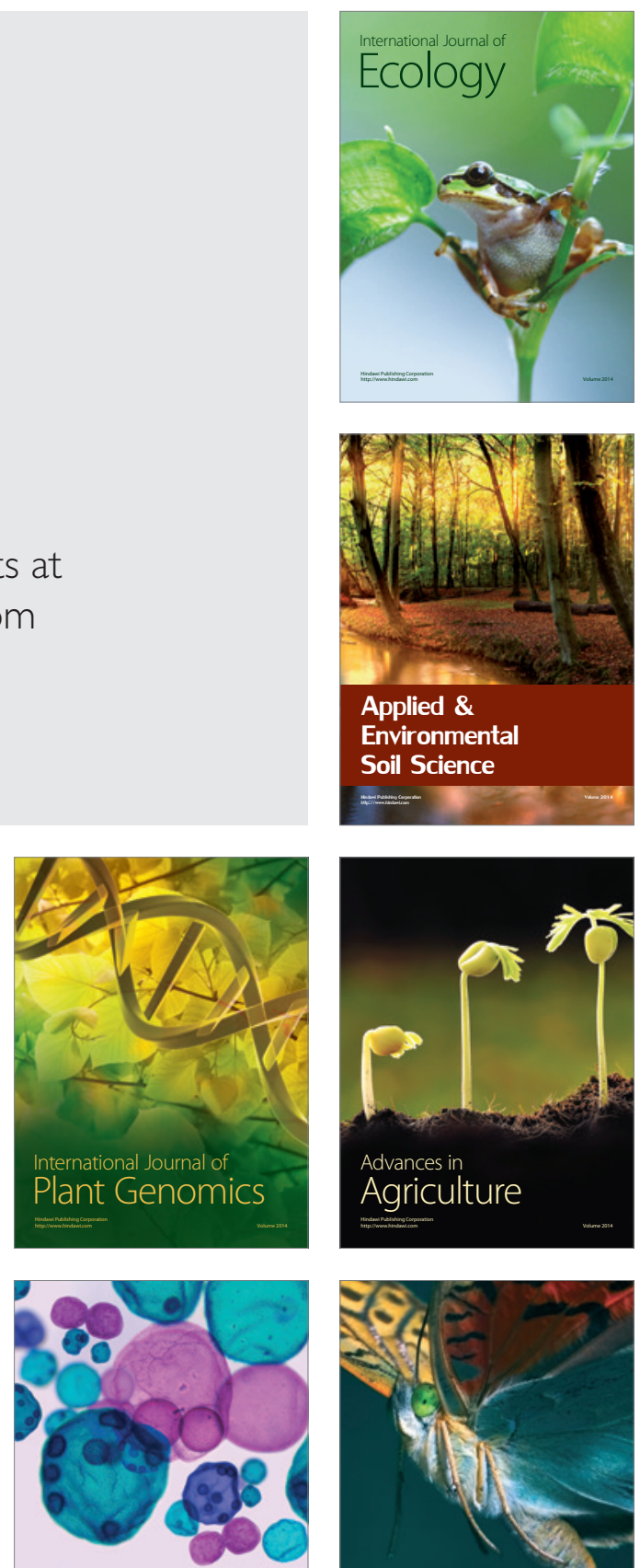

International Journal of Microbiology

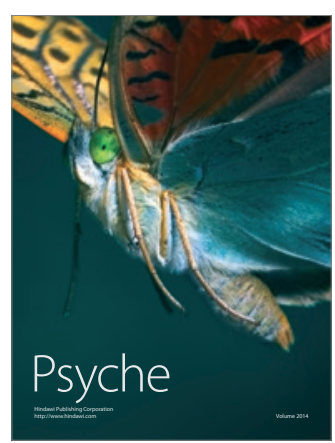

